\title{
Differences in spatial autocorrelation between four sub-populations of Alnus trabeculosa Hand.-Mazz. (Betulaceae)
}

\author{
N Miyamoto ${ }^{1}$, N Kuramoto ${ }^{2}$ and $\mathrm{H} \mathrm{Yamada}^{3}$ \\ ${ }^{1}$ Hokkaido Regional Breeding Office, Forest Tree Breeding Center, 561 Midori-machi, Bunkyodai, Ebetsu, Hokkaido, 069-0836, Japan; \\ ${ }^{2}$ Kyusyu Regional Breeding Office, Forest Tree Breeding Center, 2320 Suya Nishigoshi-Machi Kikuchi Kumamoto, 861-1102, Japan; \\ ${ }^{3}$ Forest Tree Breeding Center, 3809-1 Ishi, Juo, Taga, Ibaraki, 319-1301, Japan
}

To investigate the spatial structure of Alnus trabeculosa Hand.-Mazz, we compared three sub-populations at Imaichi in Tochigi Prefecture and one sub-population at Juo in Ibaraki Prefecture, Japan. A total of 269 trees, covering 0.71 ha in total, were mapped and genetically analyzed using nine enzyme systems encoding 13 isozyme loci. There were no significant differences between the four sub-populations in terms of $\mathrm{Na}, \mathrm{Ne}, \mathrm{H}_{\mathrm{o}}, \mathrm{H}_{\mathrm{e}}$ and $F_{\mathrm{IS}}$. However, according to spatial autocorrelation analysis, the Juo sub-population, which is younger than the others, showed an aggregation of multilocus genotypes, especially within $25 \mathrm{~m}$ radii. In contrast with the Juo sub-population, those in Imaichi showed no clear spatial structuring. In the three Imaichi sub-populations, gametic phase disequilibrium is attributable to heterogeneity of genotype frequencies, but in the Juo sub-population it seems to be due to other factors, connected with the composition of the trees in the sub-population and/or its founder population, gene flow and asexual propagation. To conserve as much as possible of the genes or genotypes in restricted areas, conservation of populations that do not show clear family structures, such as those in Imaichi, would be most effective.

Heredity (2002) 89, 273-279. doi:10.1038/sj.hdy.6800132

Keywords: Alnus trabeculosa; genetic variation; gametic phase disequilibrium; spatial autocorrelation

\section{Introduction}

Alnus trabeculosa Hand.-Mazz. is a deciduous broadleaved tree species which grows only in open swampy places. The species is sparsely distributed in the warmand intermediate-temperate zones of Honshu, with northernmost limits in Yuda in Iwate Prefecture, and Kyushu (Miyazaki Prefecture) in Japan. It is also found in the southeastern part of continental China (Kurata, 1971). Propagation is accomplished not only by sexual reproduction via seeds but also by asexual reproduction via sprouts (Handa et al, 1996). Because its habitat is dwindling and human activities are having an adverse influence, populations of the species are declining, and it is now classed as 'near threatened' (Environment Agency of Japan, 2000).

Genetic variation and especially family structure can result from several evolutionary processes including, amongst others, isolation in small patches, limited pollen or seed dispersal, selection and human influences (Sokal and Menozzi, 1982).

As a tool for analyzing family structure, spatial autocorrelation has been used in several studies of forest tree populations. For example, differences in genetic structure

Correspondence: N Miyamoto, Hokkaido Regional Breeding Office, Forest Tree Breeding Center, 561 Midori-machi, Bunkyodai, Ebetsu, Hokkaido, 069-0836, Japan. E-mail: naoruko@affrc.go.jp

Received 19 September 2001; accepted 14 May 2002 between populations with different age classes have been detected in various studies using the technique (Hamrick et al, 1993; Epperson and Alvarez-Buylla, 1997; Parker et al, 2001). The cited authors found genetic structure in the younger classes which disappeared in older classes as the populations were thinned. It also revealed striking differences in genetic structure between populations with differing histories of anthropogenic disturbance (Knowles et al, 1992; Takahashi et al, 2000). Strong structuring has also been detected using spatial autocorrelation in a population in which vegetative reproduction and limited dispersal of pollen and seeds were observed (Shapcott, 1995).

It is true that assessing subtle differences among evolutionary processes by spatial autocorrelation is unrealistic. Nevertheless, investigating family structure can help us to describe the main evolutionary forces affecting the population under study (Sokal and Menozzi, 1982), and provide fundamental information needed for selecting natural populations for conservation or sampling populations for breeding programs. Family structure should also be taken into account in order to maximize diversity, and to avoid making erroneous estimates of the diversity of populations (Epperson, 1989).

Miyamoto et al (2000) detected the existence of family structure in the Juo population of $A$. trabeculosa using spatial autocorrelation. They concluded that for both in situ and ex situ conservation of this species it is important to take into consideration the existence of family structure. 
They also suggested that the species' mode of seed dispersal and asexual propagation may be involved in the formation of family structure. However, there is no information about family structures in other populations of $A$. trabeculosa, so it is not clear whether family structure is a common phenomenon in this species, or whether any other factors, such as tree size and historical factors, influence such structure.

In this study, we investigated the genetic variation and family structure of three sub-populations in Imaichi, Tochigi Prefecture, Japan, using spatial autocorrelation, and compared them with similar data from the subpopulation in Juo, Ibaraki prefecture, to obtain fundamental information for conserving populations of this species.

\section{Materials and methods}

\section{Study site}

The A. trabeculosa population investigated at Imaichi, Tochigi Prefecture (Figure 1, Table 1) (175 m.a.s.l.; $36^{\circ} 37^{\prime} \mathrm{N}, 139^{\circ} 44^{\prime} \mathrm{E}$ ) is composed of 123 individuals. The height and diameter at breast height (d.b.h.) of all these individuals were measured and mapped. The individuals are situated in two areas (about $200 \mathrm{~m}$ apart), separated by paddy fields, roads and watercourses. The sub-population in the northern area 'sub-population $\mathrm{A}^{\text {' was desig- }}$ nated $\mathrm{AI}$, and the subpopulation in the southern area 'sub-population B' was designated BI. Within AI, trees in
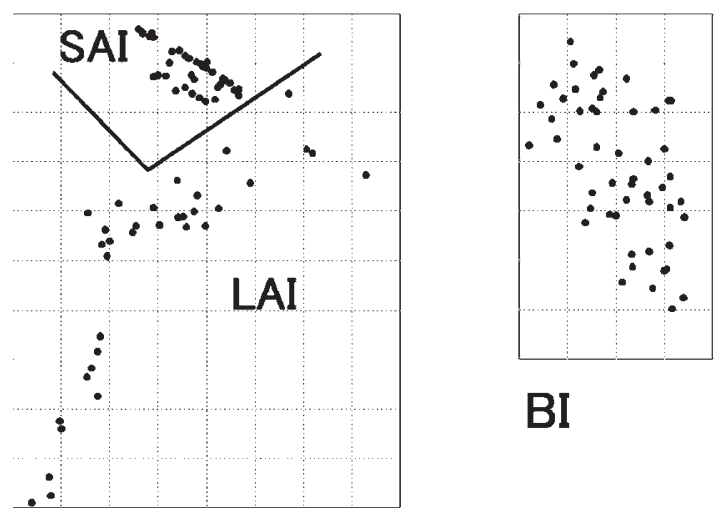

BI

AI

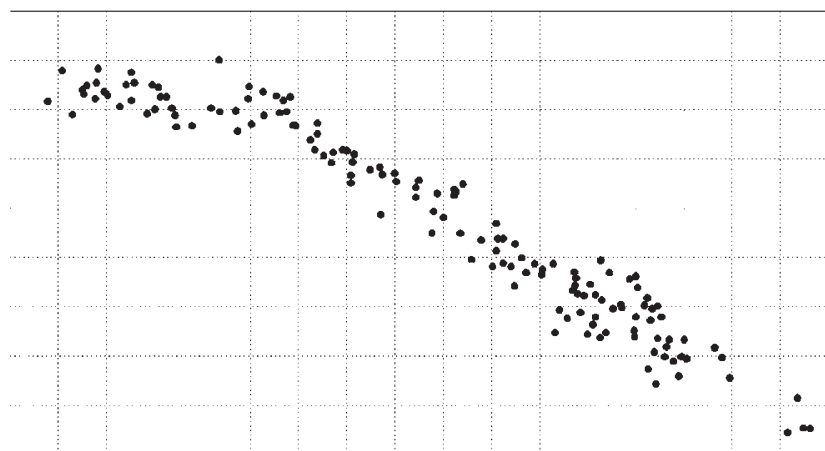

\section{JUO}

Figure 1 Geographical distribution of trees in AI (LAI and SAI), BI and JUO. Grid with dashed lines indicates $10 \mathrm{~m}$ intervals. the northeastern part (height, $16.1 \mathrm{~m} \pm 2.4$; d.b.h., $25.1 \mathrm{~cm}$ \pm 10.0 ) appear to differ substantially in age compared with those in the southwestern part (height, $10.0 \mathrm{~m} \pm 1.7$; d.b.h., $11.1 \mathrm{~cm} \pm 3.6)$. In 1972, the southwestern part of AI was reclaimed, and at that time many seeds fell onto this site from the trees that were cut down (Natsuka, 1996). The two parts of AI were separated; the northeastern part with large trees was called 'sub-population LA' (or LAI), and the southwestern part with small trees was called 'sub-population SA' (or SAI). BI was composed solely of trees of about the same size as those in LAI (height, $17.6 \mathrm{~m} \pm 1.6$; d.b.h., $24.5 \mathrm{~cm} \pm 6.1$ ).

Miyamoto et al (2000) have already described the family structure of the sub-population of $A$. trabeculosa at Juo in Ibaraki Prefecture (Figure 1, Table 1) (50 m.a.s.l.; $36^{\circ} 42^{\prime} \mathrm{N}, 140^{\circ} 42^{\prime} \mathrm{E}$; designated JUO), which is composed of 146 individuals (height, $8.9 \mathrm{~m} \pm 2.6$; d.b.h., $11.0 \mathrm{~cm} \pm$ 4.7). This sub-population is located along the course of a small river, and no sub-populations of the species are located upstream. This sub-population was with the three sub-populations at Imaichi (LAI, SAI and BI).

\section{Isozyme analysis}

Experimental samples (winter buds) were collected from all the mapped individuals in Imaichi in the winter of 1999, and stored at $-80^{\circ} \mathrm{C}$ until the enzymes were extracted. Isozyme analysis was based on the protocol described by Tsumura et al (1990). In A. trabeculosa, nine enzyme systems, encoding the 13 putative isozyme loci used in this analysis have been reported (Miyamoto et al, 2000, 2001); Aap (alanine aminopeptidase; AAP, EC 3.4.11.1), Aco (aconitase; ACO, EC 4.2.1.3), Amy-2 (amylase; AMY, EC 3.2.1), Dia-1, Dia-2, Dia-3 (diaphorase; DIA, EC 1.6.4.3), G6p (glucose-6-phosphate dehydrogenase; G6PD, EC 1.1.1.49), Got-1, Got-2 (glutamate oxaloacetate transaminase; GOT, EC 2.6.1.1), Lap (leucine aminopeptidase; LAP, EC 3.4.11.1), Pgi-1, Pgi-2 (phosphoglucoisomerase; PGI, EC 5.3.1.9) and Shd (shikimate dehydrogenase; ShDH, EC 1.1.1.25).

\section{Genetic variation}

Genetic variation was calculated for all the trees in LAI, SAI, BI and JUO percentage of polymorphic loci $(\mathrm{Pl})$, mean number of alleles per polymorphic locus $(\mathrm{Na})$, effective number of alleles per polymorphic locus $(\mathrm{Ne})$, observed heterozygosity $\left(H_{\mathrm{o}}\right)$ and expected heterozygosity $\left(H_{\mathrm{e}}\right)$ (Hamrick and Godt, 1989). The $\mathrm{Ne}$ values were derived from $1 / \Sigma p_{i}{ }^{2}$ (Kimura and Crow, 1964). The $H_{\mathrm{e}}$ values were derived by averaging $h_{\mathrm{e}}$ over 13 loci, where $\left.h_{\mathrm{e}}=2 n\left(1-\Sigma p_{i}^{2}\right) / 2 n-1\right)(\mathrm{Nei}, 1987), p_{i}$ is the frequency of the $i$ th allele at a given locus, and $n=$ sample size.

Inbreeding coefficients and gametic phase disequilibrium The inbreeding coefficient $\left(F_{\mathrm{IS}}\right)$ and heterogeneity in genotype frequencies at each locus were calculated to assess whether the observed genotype frequencies deviated from the frequencies expected under Hardy-Weinberg equilibrium. $F_{\text {IS }}$ was derived by averaging $f_{\text {is }}$ over polymorphic loci, where $f_{\text {is }}=1-h_{\mathrm{o}} / h_{\mathrm{e}}, h_{\mathrm{e}}$ is expected heterozygosity and $h_{\mathrm{o}}$ is observed heterozygosity. We also calculated the gametic phase disequilibrium between all pairs of detected loci. Heterogeneity in genotype frequencies at each of the polymorphic loci and gametic phase disequilibrium between all pairs of 13 loci were examined using the chi-squared test of the GDA program version 1.0 (Lewis and Zaykin, 2001). 
Table 1 Environmental characteristics for the four Alnus trabeculosa sub-populations

\begin{tabular}{|c|c|c|c|c|c|c|c|c|}
\hline Population & Altitude (m) & Latitude & Longitude & No. of trees & Area $\left(m^{2}\right)$ & Density (/ha) & Height (m) & d.b.h. (cm) \\
\hline LAI & 175 & $36^{\circ} 41^{\prime} \mathrm{N}$ & $140^{\circ} 42^{\prime} \mathrm{E}$ & 34 & 1400 & 243 & $16.1 \pm 2.4$ & $25.1 \pm 10.0$ \\
\hline SAI & - & - & - & 37 & 500 & 740 & $10.0 \pm 1.7$ & $11.1 \pm 3.6$ \\
\hline BI & - & - & - & 52 & 1700 & 306 & $17.6 \pm 1.6$ & $24.5 \pm 6.1$ \\
\hline JUO & 50 & $36^{\circ} 37^{\prime} \mathrm{N}$ & $139^{\circ} 44^{\prime} \mathrm{E}$ & 146 & 3500 & 417 & $8.9 \pm 2.6$ & $11.0 \pm 4.7$ \\
\hline
\end{tabular}

d.b.h.: diameter at breast height.

\section{Data analysis}

Spatial genetic structure within sub-populations was assessed with estimates of coancestry (Cockerham, 1969) between all possible pairs of individuals at different interplant distances. In order to estimate coancestry, genotypes for individuals were first expressed as allele frequencies of $1.0,0.5$, or 0.0 , depending on whether their genotype comprised 2, 1 , or 0 copies of the respective alleles (Heywood, 1991). Estimates of coancestry $\left(\rho_{i j}\right)$ were then calculated as:

$$
\hat{\rho}_{i j}=\frac{\sum_{i j}\left(p_{i}-\bar{p}\right)\left(p_{j}-\bar{p}\right)}{k \bar{p}(1-\bar{p})}+\frac{2}{(8 k+1)^{0.5}},(i<j)
$$

where $p_{i}$ and $p_{j}$ are the frequencies of homologous alleles at a locus for individuals $i$ and $j ; p$ is the mean frequency for that allele; and $k=n(n-1) / 2$, which gives the number of possible pairs between $n$ individuals located in each distance class (Loiselle et al, 1995). The second term in the equation adjusts for bias associated with a finite sample size, which causes the estimate of coancestry to be zero for a population in Hardy-Weinberg equilibrium. The correlation between pairs of plants in their frequencies of homologous alleles at a given locus $\left(\rho_{i j}\right)$ in an outbreeding population $\left(F_{\mathrm{IS}}=0\right)$ has expected values of 0.125 and 0.0625 for half-sibs and first cousins, respectively. A combined multilocus estimate of coancestry can be obtained by weighting the values for each locus by its polymorphic index, $\Sigma p_{i}\left(1-p_{i}\right)$. Weights for individual loci were also adjusted for differences in sample size due to missing genotypes (Loiselle et al, 1995). Multilocus coancestry estimates have a sound foundation in population genetics theory and provide a natural means of summarizing data over alleles at a locus and over loci to provide a more powerful test for spatial genetic structure (Heywood, 1991). Therefore, multilocus estimates of coancestry were calculated at $5 \mathrm{~m}$ interplant-distance increments for each sub-population. Tests of significance for estimated values of $\rho_{i j}$ were performed using randomization procedures to generate populations under the null hypothesis of no spatial structure. In each subpopulation, intact multilocus genotypes were randomly drawn, with replacement, from the sampled data and assigned to points occupied by plants. New $\rho_{i j}$ values were then calculated. This randomization procedure was repeated 399 times for each sub-population, giving (together with the originally sampled data) $400 \rho_{i j}$ values, from which $95 \%$ and $99 \%$ intervals were constructed. The procedure tests the significance of the correlation in multilocus genotypes at each distance interval (Slatkin and Arter, 1991). The software developed by Nason $(1997,1998)$ for the autocorrelation analyses of coancestry was used.

\section{Results}

\section{Isozyme analysis}

Thirty alleles were detected, but for three loci (Aco, Dia-1 and Pgi-2) no variation was in any of the sub-populations (Table 2). All other loci had at least two alleles (the maximum being four alleles at Shd). Four out of 10 polymorphic loci were fixed in some of the sub-populations, but the other six (Aap, Amy-2, Dia-3, G6p, Lap and Poi1) showed segregation in every population at the $95 \%$ polymorphic level. Some alleles were observed in only one sub-population (Shd ${ }^{c}$ and Shd $d^{e}$ in SAI; Dia-2 ${ }^{a}$ and $\mathrm{Lap}^{c}$ in JUO).

\section{Comparison of the growth of individuals between the populations}

The LAI and BI populations were almost the same in terms of height and d.b.h. (Figure 2; Table 1). However, these two populations differed in size from the SAI and JUO sub-populations, which were also composed of similarly sized (and thus similarly aged) individuals.

\section{Genetic variation}

There were no significant differences in genetic variation parameters amongst the four sub-populations (Table 3).

\section{Inbreeding coefficients, heterogeneity and gametic phase disequilibrium}

The inbreeding coefficients $\left(F_{\text {IS }}\right)$ were -0.112 in LAI, 0.001 in SAI, -0.085 in $\mathrm{BI}$ and -0.018 in $\mathrm{JUO}$, there were no significant differences in these parameters between the four sub-populations. Heterogeneity of genotype frequencies was detected at Pgi-1 in LAI, and at Aap in SAI and BI. But when these loci were excluded, no gametic phase disequilibrium between the pairs of loci was observed in LAI, SAI or between any pairs except one $(G 6 p / G o t-2)$ in BI. In contrast to the three sub-populations in Imaichi, we did not observe heterogeneity of genotype frequencies in JUO, but we did detect gametic phase disequilibrium between 12 pairs of loci (Aap/Dia-2, Aap/Dia-3, Aap/Got-2, Aap/Pgi-1, Aap/G6p, Aco/G6p, Amy2/Lap, Dia-1/G6p, Dia-2/Dia-3, Dia-2/Got-2, Dia-2/G6p, Got$2 / G 6 p)$ in this sub-population.

\section{Fine-scale genetic structure}

In the LAI and SAI sub-populations, coancestry values were within the range of $99 \%$ confidence limits in all of the distance classes (Figure 3). In the BI sub-population too, the coancestry values were not significantly different from zero, with the exception of significant positive and negative correlations at the closest distance class and 45 
Table 2 Allele freuencies in the four Alnus trabeculosa sub-populations

\begin{tabular}{|c|c|c|c|c|c|c|}
\hline Enzyme & Locus & Allele & $L A I$ & $S A I$ & $B I$ & JUO \\
\hline AAP & Aap & $\begin{array}{l}a \\
b \\
c \\
d\end{array}$ & $\begin{array}{l}0.367 \\
0.017 \\
0.550 \\
0.067\end{array}$ & $\begin{array}{l}0.157 \\
0.029 \\
0.643 \\
0.171\end{array}$ & $\begin{array}{l}0.365 \\
0.048 \\
0.423 \\
0.163\end{array}$ & $\begin{array}{c}0.837 \\
0.059 \\
0.104 \\
-\end{array}$ \\
\hline AMY & $A m y-2$ & $\begin{array}{l}a \\
b\end{array}$ & $\begin{array}{l}0.191 \\
0.809\end{array}$ & $\begin{array}{l}0.203 \\
0.797\end{array}$ & $\begin{array}{l}0.183 \\
0.817\end{array}$ & $\begin{array}{l}0.190 \\
0.810\end{array}$ \\
\hline DIA & Dia-2 & $\begin{array}{l}a \\
b\end{array}$ & $\begin{array}{c}- \\
1.000\end{array}$ & $\overline{-}$ & $\overline{-}$ & $\begin{array}{l}0.117 \\
0.883\end{array}$ \\
\hline & Dia-3 & $\begin{array}{l}a \\
b \\
c\end{array}$ & $\begin{array}{l}0.235 \\
0.647 \\
0.118\end{array}$ & $\begin{array}{l}0.214 \\
0.729 \\
0.057\end{array}$ & $\begin{array}{l}0.212 \\
0.615 \\
0.173\end{array}$ & $\begin{array}{l}0.048 \\
0.767 \\
0.185\end{array}$ \\
\hline G6PD & G6p & $\begin{array}{l}a \\
b\end{array}$ & $\begin{array}{l}0.647 \\
0.353\end{array}$ & $\begin{array}{l}0.784 \\
0.216\end{array}$ & $\begin{array}{l}0.596 \\
0.404\end{array}$ & $\begin{array}{l}0.308 \\
0.692\end{array}$ \\
\hline GOT & Got-1 & $\begin{array}{l}a \\
b\end{array}$ & $\begin{array}{l}0.941 \\
0.059\end{array}$ & $\begin{array}{c}1.000 \\
-\end{array}$ & $\begin{array}{c}1.000 \\
-\end{array}$ & $\begin{array}{l}0.993 \\
0.007\end{array}$ \\
\hline & Got-2 & $\begin{array}{l}a \\
b\end{array}$ & $\begin{array}{l}0.044 \\
0.956\end{array}$ & $\overline{-}$ & $\begin{array}{l}0.127 \\
0.873\end{array}$ & $\begin{array}{l}0.141 \\
0.859\end{array}$ \\
\hline LAP & Lap & $\begin{array}{l}a \\
b \\
c\end{array}$ & $\begin{array}{c}0.941 \\
0.059 \\
-\end{array}$ & $\begin{array}{c}0.973 \\
0.027 \\
-\end{array}$ & $\begin{array}{c}0.673 \\
0.327 \\
-\end{array}$ & $\begin{array}{l}0.962 \\
0.028 \\
0.010\end{array}$ \\
\hline PGI & Pgi-1 & $\begin{array}{l}a \\
b \\
c\end{array}$ & $\begin{array}{l}0.676 \\
0.029 \\
0.294\end{array}$ & $\begin{array}{c}0.797 \\
- \\
0.203\end{array}$ & $\begin{array}{l}0.510 \\
0.096 \\
0.394\end{array}$ & $\begin{array}{c}0.886 \\
0.114 \\
-\end{array}$ \\
\hline ShDH & Shd & $\begin{array}{l}a \\
b \\
c \\
e\end{array}$ & $\begin{array}{c}- \\
1.000 \\
- \\
-\end{array}$ & $\begin{array}{l}0.014 \\
0.932 \\
0.014 \\
0.041\end{array}$ & $\begin{array}{c}0.106 \\
0.894 \\
- \\
-\end{array}$ & $\begin{array}{c}0.090 \\
0.910 \\
- \\
-\end{array}$ \\
\hline
\end{tabular}

$\mathrm{m}$, respectively. In contrast, the coancestry coefficients in the JUO sub-population were higher than the expected range in the first five distance classes, falling into the expected interval only at the sixth distance class (upper limit, $30 \mathrm{~m}$ ). These data indicate that individuals within $25 \mathrm{~m}$ of each other may tend to be genetically similar in the JUO sub-population.

\section{Discussion}

Based on the data of Miyamoto et al (2001), the mean parameters of genetic variation within seven previously investigated populations of $A$. trabeculosa in Japan $P l=$ 64.3, $\mathrm{Na}=2.76, \mathrm{Ne}=1.54$ and $H_{\mathrm{e}}=0.199$ are roughly intermediate in comparison with the values obtained for the four sub-populations in this study. According to the ANOVA for the values of genetic variation, there were no significant differences between the four sub-populations, four sub-populations have almost the same level of within-population genetic variation.

However, the spatial autocorrelation revealed striking differences among these sub-populations. The JUO subpopulation showed an aggregation of multilocus genotypes, which was not seen in the other sub-populations. This indicates the possible existence of family structure in the JUO sub-population, which is consistent with observations reported by Miyamoto et al (2000), but not in the others. The data suggest that the spatial range of the autocorrelation for individuals of the JUO sub-population is about $25 \mathrm{~m}$.

JUO and SAI are composed of trees with very similar sizes and these two sub-populations have very similar levels of genetic variation. However, the former showed a remarkable tendency for individuals displaying autocorrelation to be located close to each other, while the latter did not. In several species, the genetic structure in younger populations is reported to disappear in older populations as they are thinned (Hamrick et al, 1993; Epperson and Alvarez-Buylla, 1997; Parker et al, 2001). In the same way, the only sub-population that showed genetic structure was JUO; which is relatively young. However, the SAI sub-population, which is of similar age to JUO, did not show obvious genetic structure. Hence, we can speculate that in each population, spatial structures have been affected by various factors such as the composition of the mother population, micro-geographic features and climatic factors.

Heterogeneity of genotype frequencies in the three Imaichi sub-populations and gametic phase disequilibrium in all four sub-populations were observed. The gametic phase disequilibria of combined genotype frequencies between the Pgi-1 locus and other loci at LAI, the Aap locus and other loci at SAI, and the Aap locus and other loci at BI are attributable to the heterogeneity 

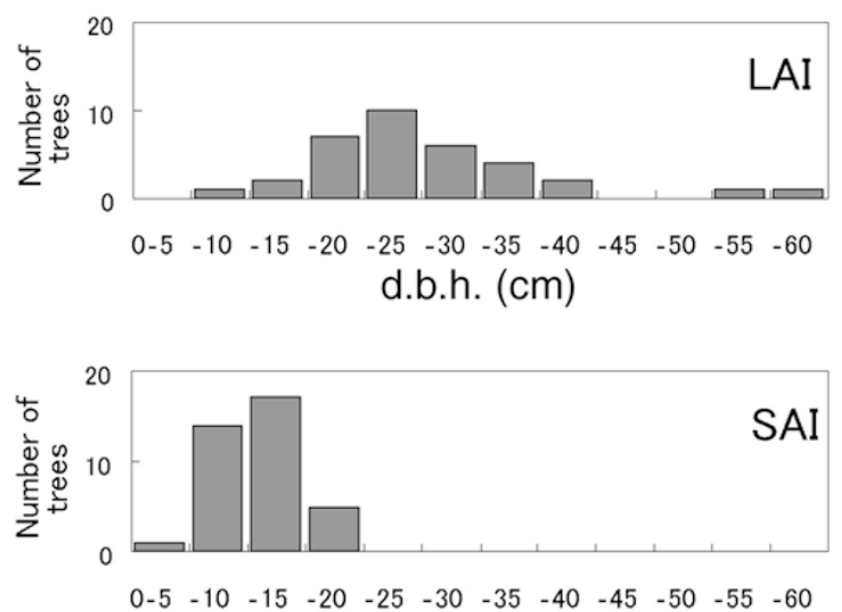

d.b.h. $(\mathrm{cm})$

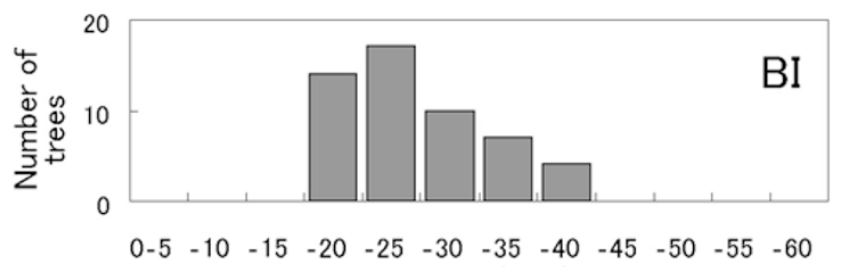

d.b.h. $(\mathrm{cm})$

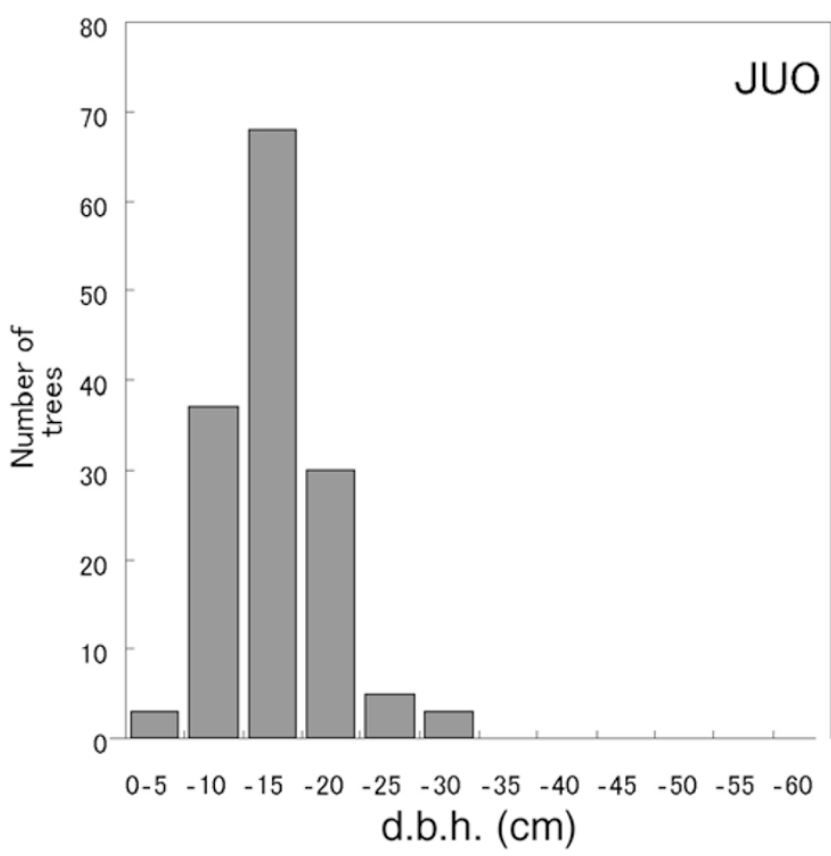

Figure 2 Distributions of diameter at breast height (d.b.h.) in the four Alnus trabeculosa sub-populations.

of genotype frequencies at these loci. However, in the JUO sub-population gametic phase disequilibria in 12 pairs of combinations were detected, despite the absence of heterogeneity of genotype frequencies. Gametic phase disequilibrium may be due to various causes, including the admixture of two or more populations that differ in genetic composition, residual disequilibrium persisting from gametic phase disequilibrium in the founder popu-
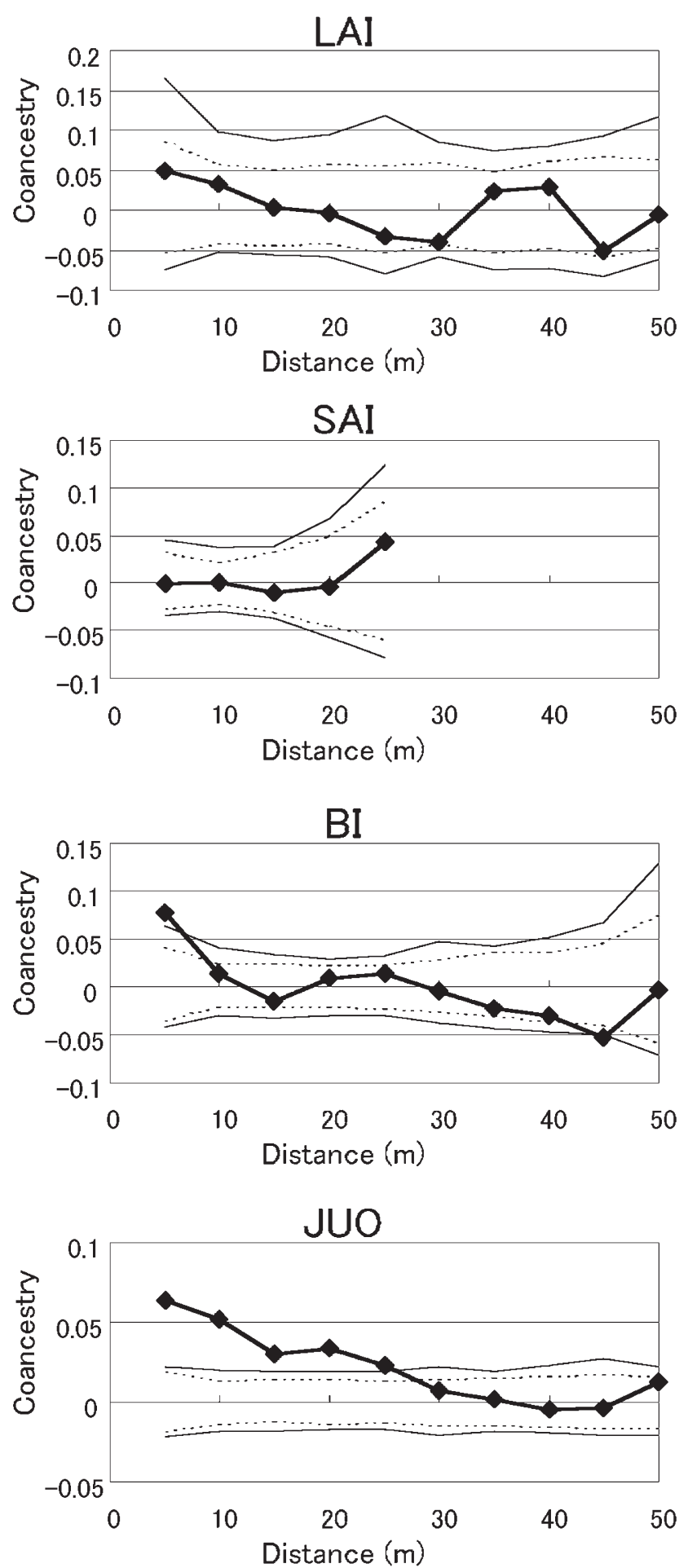

Figure 3 Spatial correlograms of coancestry coefficients $\left(\rho_{i j}\right)$ for the four Alnus trabeculosa sub-populations. Dashed lines (95\%) and solid lines (99\%) represent upper and lower confidence limits for zero relationships.

lation, or selection favoring individuals with specific pairs of genotypes. Sometimes it is also caused by chance in small populations. Furthermore, gametic phase disequilibrium tends to be maintained through generations. If the cause of this kind of gametic phase disequilibrium is removed, it will decrease slowly, but persist for a long 
Table 3 Genetic variation parameters $\left(\mathrm{Pl}, \mathrm{Na}, \mathrm{Ne}, \mathrm{H}_{\mathrm{o}}, H_{\mathrm{e}}\right.$ and $\left.F_{\mathrm{IS}}\right)$ for the four Alnus trabeculosa sub-populations (means with standard errors in parentheses)

\begin{tabular}{lrrrrrr}
\hline & $P l$ & $N a$ & $N e$ & $H_{\mathrm{o}}$ & $H_{\mathrm{e}}$ & \multicolumn{1}{c}{$F_{\text {IS }}$} \\
\hline & & & & & & \\
LAI & 61.5 & $2.5(0.3)$ & $1.60(0.16)$ & $0.225(0.070)$ & $0.203(0.063)$ & $-0.112(0.034)$ \\
SAI & 53.8 & $2.7(0.4)$ & $1.50(0.14)$ & $0.165(0.054)$ & $0.165(0.055)$ & $0.001(0.049)$ \\
BI & 61.5 & $2.5(0.3)$ & $1.89(0.21)$ & $0.287(0.075)$ & $0.265(0.071)$ & $-0.085(0.037)$ \\
JUO & 76.9 & $2.3(0.2)$ & $1.33(0.07)$ & $0.181(0.044)$ & $0.177(0.042)$ & $-0.018(0.027)$ \\
\hline
\end{tabular}

$\mathrm{Pl}=$ percentage of polymorphic loci; $\mathrm{Na}=$ mean number of alleles per polymorphic locus; $\mathrm{Ne}=$ effective number of alleles per polymorphic locus; $H_{\mathrm{o}}=$ observed hyeterozygosity; $H_{\mathrm{e}}=$ expected heterozygosity; $F_{\mathrm{IS}}=$ inbreeding coefficient.

time. On the other hand, heterogeneity of genotype frequencies may be caused by non-random mating or selection, but it will be cancelled by one random mating in these cases (Falconer, 1989; Hartl and Clark, 1997). Takahashi et al (2000) investigated the gametic phase disequilibrium in two populations of Japanese beech (Fagus crenata) that have different histories in terms of cutting. A population cut in the past showed gametic phase disequilibrium, whereas the other, uncut population showed no such disequilibrium. The cited authors point out that if the natural composition of the gene set is assumed to be the most highly adapted to a given environment, gametic phase disequilibrium implies reductions in the adaptability of populations in succeeding generations, which could be detrimental to conservation of important genetic resources. The heterogeneity and gametic phase disequilibrium data gathered for the JUO sub-population indicate that random mating may have occurred in its mother population, but there are distortions in the composition of the trees in the sub-population and/or its founder population. Moreover, asexual propagation may occur in JUO (Miyamoto et al, 2000), which may also contribute to the gametic phase disequilibrium.

SAI occupies a site that was reclaimed in 1972 (Natsuka, 1996), when the mother trees of the trees now forming this sub-population were probably cut down. Indeed, in SAI we detected two alleles $\left(S h d^{c}, S h d^{\mathrm{e}}\right)$ that were not found in LAI or BI, despite the proximity of these sub-populations to SAI, indicating that the mother trees of the SAI sub-population do not exist now or are located outside of AI and BI.

As we noted above, differences between the spatial structure and the probable cause of gametic phase disequilibrium were detected among the sub-populations in Imaichi and Juo. Another possible reason for these differences is that there are a lot more small sub-populations of the species around the sites we studied at Imaichi (Natsuka, 1996) than there are at JUO. So, we can speculate that fewer trees may have contributed genetically to the members of the JUO sub-population. In contrast with the case of the JUO sub-population, dispersal of pollen by the wind, or migration of seeds by wind and/or water from other sub-populations might homogenize the subpopulations genetically in Imaichi. Differences in the size of gene sources may be one of the reasons for the differences detected between the Imaichi and Juo sub-populations.

From the conservation perspective, all the populations of this species cannot be conserved. So, to conserve as much as possible of the species' genes and genotypes, information about their distribution within populations is very helpful. In this study, the three sub-populations at Imaichi did not show any clear indications of family structure. These populations have fewer individuals and cover smaller areas than the JUO population. However, it seems highly likely that the populations at Imaichi are composed of genetically varied individuals. For gene and genotype conservation, conserving such populations should be valuable and effective. For the JUO sub-population, however, the existence of family structure indicates that conserving just a part of it will not be sufficient for maintaining its genetic variation. Doing so would risk losing its genetic variation through selection and genetic drift that will occur in the future. Moreover, some of the individuals in the SAI and JUO sub-populations are considered to host rare alleles. Conserving such individuals via in situ and/or ex situ conservation \&would be important. To obtain further information concerning $A$. trabeculosa for establishing effective conservation measures, researching the spatial structure in other populations, and evaluation of the gene flow and asexual reproduction ability of this species would be needed.

\section{Acknowledgements}

The authors are particularly grateful to Mr A Shinohara for access to the sites (in Imaichi) and useful information, to Mr M Kikuchi , Mr J Otsuka and Mr Y Ueno for their help in collecting samples and to Ms K Tanaka and Ms Y Miyata for their assistance in the laboratory.

\section{References}

Cockerham CC (1969). Variance of gene frequencies. Evolution 23: 72-84.

Environment Agency of Japan (2000). Threatened Wildlife of Japan. -Red Data Book- 2nd edn. Vascular Plants. Japan Wildlife Research Center: Tokyo. Vol 8, p 626. (in Japanese)

Epperson BK (1989). Spatial patterns of genetic variation within plant populations. In: Brown AHD, Clegg MT, Kahler AL, Weir BS (eds) Plant Population Genetics, Breeding and Genetic Resources, Sinauer Associates: Sunderland, MA, pp 229-253.

Epperson BK, Alvarez-Buylla ER (1997). Limited seed dispersal and genetic structure in life stages of Cecropia obtusifolia. Evolution 51: 275-282.

Falconer DS (1989). Introduction to Quantitative Genetics, 3rd edn. John Wiley and Sons: New York.

Hamrick JL, Godt MJW (1989). Allozyme diversity in plant species. In: Brown AHD, Clegg MT, Kahler AL, Weir BS (eds) Plant Population Genetics, Breeding and Genetic Resources, Sinauer Associates: Sunderland, MA, pp 43-63.

Hamrick JL, Murawski DA, Nason JD (1993). The influence of seed dispersal mechanisms on the genetic structure of tropical tree populations. Vegetatio 107/108: 281-297. 
Handa T, Senda M, Hoshi H, Nishimura K (1996). The Alnus trabeculosa population at Juo in Ibaraki Prefecture (I). Trans Jpn For Soc 107: 145. (in Japanese)

Hartl DL, Clark AG (1997). Principles of Population Genetics, 3rd edn. Sinauer Associates: Sunderland, MA.

Heywood JS (1991). Spatial analysis of genetic variation in plant populations. Ann Rev Ecol Syst 22: 335-355.

Kimura M, Crow JF (1964). The number of alleles that can be maintained in a finite population. Genetics 49: 725-738.

Knowles P, Perry DJ, Forster HA (1992). Spatial genetic structure in two tamarack (Larix laricina (Du Roi) K. Kcoh) populations with differing establishment histories. Evolution 46: 572-576.

Kurata S (1971). Illustrated Important Forest Trees of Japan. Chikyu shuppan: Tokyo. Vol 3, pp 13-13. (in Japanese)

Lewis PO, Zaykin D (2001). Genetic Data Analysis. A computer program for the analysis of allelic data. Version 1.0 (d16c). Free program distributed by the authors over the internet from http://lewis.eeb.uconn.edu/lewishome/software.html

Loiselle BA, Sork VL, Nason J, Graham C (1995). Spatial genetic structure of a tropical understory shrub Psychotria officinalis (Rubiaceae) Am Bot 82: 1420-1425.

Miyamoto N, Kuramoto N, Hoshi H (2001). Genetic variation of Alnus trabeculosa populations in Japan. J Jpn For Soc 6: 247-251.

Miyamoto N, Yamamoto N, Hoshi H, Handa T (2000). Isozyme polymorphisms and family structure of Alnus trabeculosa Hand.-Mazz. (Betulaceae) population at Juo, Ibaraki Prefecture. J Jpn For Soc 82: 72-79. (in Japanese with English summary)

Nason JD (1997). FijAnal. A computer program for the analysis of spatial autocorrelation. Version 2.1. Free program distributed by the author over the internet from http://www. nceas.ucsb.edu/papers/geneflow/software/

Nason JD (1998). BS- fij. A computer program for the analysis of significance tests. Version 2.1. Free program distributed by the author over the internet from http://www.nceas.ucsb.edu/ papers/geneflow/software/

Natsuka F (1996). Distribution of Alnus trabeculosa at Imaichi and Kanuma in Tochigi Prefecture. Bull Tochigi Pref Mus 13: 109114. (in Japanese)

Nei M (1987). Molecular Evolutionary Genetics. Columbia University Press: New York.

Parker KC, Hamrick JL, Parker AJ, Nason JD (2001). Fine-scale genetic structure in Pinus clausa (Pinaceae) populations: effects of disturbance history. Heredity 87: 99-113.

Shapcott A (1995). The spatial genetic structure in natural populations of the Australian temperate rainforest tree Atherosperma moschatum. Heredity 74: 28-38.

Slatkin M, Arter HE (1991). Spatial autocorrelation methods in population genetics. Am Nat 138: 449-517.

Sokal RR, Menozzi P (1982). Spatial autocorrelation of HLA frequencies in Europe support demic diffusion of early farmers. Am Nat 119: 1-17.

Takahashi M, Mukouda M, Koono K (2000). Differences in genetic structure between two Japanese beech (Fagus crenata Blume) stands. Heredity 84: 103-115.

Tsumura Y, Tomaru N, Suyama Y, Na'iem M, Ohba K (1990). Laboratory manual of isozyme analysis. Bull Tsukuba Univ Forests 6: 63-95. (in Japanese) 